'llu. Revista de Ciencias de las Religiones

ISSN: $1135-4712$

http://dx.doi.org/10.5209/ILUR.61019

\title{
La obcecación creencial y su tratamiento por medio de la comun(icac)ión experiencial y de la palabra invocadora ${ }^{1}$
}

\author{
José Barrientos Rastrojo ${ }^{2}$
}

Recibido: 27 de junio de 2016 / Aceptado: 8 de mayo de 2017

Resumen. Los recursos de una racionalidad lógico-argumental como la lógica, el análisis conceptual, la definición o la argumentación estructurada son suficientes para resolver muchos conflictos religiosos; sin embargo, manifiestan limitaciones para enfrentar muchas luchas de este ámbito. Una causa de esta ineficacia se debe a que el marco desde el que se discute allí no es ideacional sino creencial. La disolución de las creencias (o, inversamente, su generación) requiere un tipo de racionalidad diferente a la anterior: la experiencia y la comunicación son sus principales bastiones. Este artículo estudia las limitaciones de la racionalidad lógico-argumental y cómo el complemento de la experiencialidad puede ayudar al abordaje del conflicto religioso no fundado en una base ideacional.

Palabras clave: Experiencia, creencia, religión, comunidad, comunicación.

\section{[en] The stubborn of believers and its treatment through the experiential comun(icat)ion and the invoced word}

\begin{abstract}
Tools of a logical-argumentive rationality such as logic, conceptual analysis, definition or structured arguments are useful to sort out many religious conflicts; however, they are ineffective to resolve others. One reason for this unfitness is that the framework from which the second ones are discussed is not ideational but they belong to the believe world. The dissolution of beliefs (or, conversely, their building) requires a kind of rationality different to the logical-argumentative one: experience and communication will be their main bastions. This paper studies the limits of logicalargumentative rationality and it reflects on how experienciality can help to face religious conflicts not based on ideational basis.
\end{abstract}

Keywords: Experience, belief, religion, community, communication.

Sumario. 1. Planteamiento del problema. 1.1. Modos de comprender: de las hermenéuticas subjetivas a las ontológicas. 1.2. Modos de comprender II: ontologización hermenéutica. 1.3. Abriendo el escenario: ideas y creencias. Correligionarios de creencias opuestas. 1.4. La dificultad de disolver las creencias. 2. La experiencia. 2.1. El viaje experiencial. 2.2. El producto cognoscitivo de la experiencia: la evidencia. 3. Conclusión y camino: la mudanza de las creencias en la comun(icac)ión. 3.1. Los problemas con la definición y con la palabra instrumental o no invocadora. 3.2. De la comunicación a

1 Este artículo se desarrolla en el marco del proyecto de investigación "Can wisdom be learned in several contexts?", financiado por la John Templeton Foundation, y del proyecto de innovación docente "El diario autobiográfico como recurso experiencial en el aula". Agradecemos las indicaciones de los evaluadores ciegos de Ilu, cuyas correcciones y sugerencias han servido para mejorar este trabajo y para incentivar nuevas vías de investigación de José Barrientos Rastrojo.

2 Universidad de Sevilla (España).

Correo electrónico: barrientos@us.es 
la comunión I: la relación. 3.3. De la comunicación a la comunión II: la palabra invocadora. 3.4. De la obcecación de creencias a la apertura de la comunión. 4. Bibliografía.

Cómo citar: Barrientos Rastrojo, J. (2018), La obcecación creencial y su tratamiento por medio de la comun(icac)ión experiencial y de la palabra invocadora, en 'Ilu. Revista de Ciencias de las Religiones $23,13-30$.

\section{Planteamiento del problema}

\subsection{Modos de comprender: de las hermenéuticas subjetivas a las ontológicas}

La historia de la hermenéutica explica el acto comprensivo desde diferentes modelos. Por un lado, se encuentran las interpretaciones basadas en que el sujeto descifra el contenido de un texto. Se encuentran en este grupo las exégesis bíblicas que abarcan desde aproximaciones alegóricas, como las de Filón de Alejandría ${ }^{3}$, y las analógicas como las de Orígenes ${ }^{4}$, hasta las literales, como las de Martín Lutero pasando por aquellas generadas por sentimientos religiosos, como las del pietismo ${ }^{6}$ o las de Rambach ${ }^{7}$, o aquellas que nacen a partir de una transposición del texto a los usos y costumbres de las culturas en que se escribió, esto es, trasladar el texto a tribus contemporáneas que viven como aquellos grupos y extraer la interpretación válida entre varias posibles, tarea que fue realizada por S.J. Baumgartem o David Michaelis 8 .

La relevancia del sujeto para el Romanticismo provocó que ciertos pensadores se detuvieran de modo preciso en su psique en el acto hermenéutico. Se ha de subrayar aquí a Scheleiermacher, quien señala que «la tarea hermenéutica consiste en reproducir todo el curso interno de la actividad compositiva del escritor ${ }^{9}$. A tal fin, la interpretación debe añadir a la intelección racional la subtilitas inteligendi, una agudeza de visión que excede las fronteras de una interpretación basada exclusivamente en la reflexión racionalista, esto es, la basada en el argumento. Desde estas prerrogativas, se empieza a explicar que la forma de describir la compresión del ser humano y de los objetos es diferente, es decir, aquí crece la semilla de la diferencia entre las ciencias de la naturaleza y las ciencias del espíritu: la aprehensión empírica, la estructuración matemática de lo real y la observación objetiva son suficientes para acercarse al fenómeno gravitatorio que hace que la tierra atraiga los cuerpos, pero resulta ineficaz para explicar la atracción entre el amante y el amado y para dar cuenta del motivo que provoca que la lágrima, pues éste es más que el resultado de la expulsión de líquido por una glándula. Pierre Enmanuelle apuntaba que «analizar intelectualmente un símbolo es como pelar una cebolla para encontrarla» ${ }^{10}$, lo cual coincide con lo que aquí se defiende, puesto que el símbolo es un producto humano cuya comprensión no se presta, exclusivamente, a

\footnotetext{
Cfr. Grondin 1999, 52-55.

Cfr. Ferraris 2000, 21-23.

Cfr. Grondin 1999, 70-73.

Cfr. Gondin 1999, 97-100.

Cfr. Ferraris 2000, 58-60.

Cfr. Ferraris 2000, 73-77.

Scheleiermacher 1999, 75

Pierre Emmanuelle citado en Durand 1968, 47.
} 
la disección intelectual; por el contrario, resulta más proclive a la comprensión por inmersión en su realidad ${ }^{11}$. En este sentido, Dilthey y Droysen defienden como marcos oportunos para la comprensión de lo humano sus productos culturales: la literatura, la pintura, la escultura o los fenómenos culturales en general ${ }^{12}$. Así, la comprensión del romanticismo tardío español sería accesible desde la zambullida en la poesía de Gustavo Adolfo Bécquer.

Un paso posterior en nuestra somera historia de la hermenéutica nos sumerge en la hermenéutica ontológica del siglo XX. A partir de los trabajos de Heidegger ${ }^{13} \mathrm{o}$ Gadamer $^{14}$, la comprensión como acto construido por un sujeto empieza a quebrar$\mathrm{se}^{15} \mathrm{y}$ se empieza a reflexionar en la posibilidad de generar una hermenéutica que lo trascienda o una que no tenga en él su punto de partida. De hecho, la hermenéutica subjetiva posee la limitación fenoménica, esto es, no alcanzaría nunca la interpretación definitiva o al noúmeno puesto que cada perspectiva está incardinada apriorísticamente por el tiempo y el espacio del intérprete. El subjetivismo aboca a un relativismo que (1) acarrea relativismo o equivocismo (en el sentido beuchotiano ${ }^{16}$ ) (2) impide el diálogo debido al solipsismo implícito en la propia perspectiva y (3) incapacita para la acción porque, además, no sería posible establecer una jerarquía de las ópticas en juego.

En el seno de este impasse, la solución heideggeriana es cambiar el punto de partida: que no sea el sujeto quien imponga su esquema comprensivo al objeto sino que dejemos a éste último se defina por sí mismo y nos diga qué es. He aquí el eje de las hermenéuticas ontológicas.

Heidegger se percata de que el objeto ha sido una construcción humana, las «botas» de una campesina se reducen a su función y cuándo su uso las hace inservibles abandona su ser como «botas» y se convierten en «basura» ${ }^{17}$. Ahora bien, ¿no poseen las botas un ser en sí mismo allende la función que le impone el sujeto? La respuesta del alemán es afirmativa y, añade, hay un tipo de sujeto que capta ese sentido propio que emana de la realidad: el artista. Cuando el pintor nos ofrece las botas, nos las dice en su pintura no nos ofrece una visión particular de la bota sino que, para hacerlas posibles, ha tenido que disolverse en ellas, dejar que éstas se hagan cargo de sus manos y pinceles y, en última instancia, permitir que el calzado de pinte a sí mismo por medio de él. Siendo esto así, el artista no ofrece su versión de las botas sino que se anula para que éstas ofrezcan su cara auténtica.

Desde este marco, la interpretación exigirá en la persona disposiciones que lo silencien y que activen sus capacidades de escucha en lugar de crear una tramoya exegética o histórica que descifre el texto. La finalidad será que el objeto se imponga

11 El símbolo es un caso clásico que explica la frase de Lacoste: "El mundo se ofrece simultáneamente como próximo y lejano" (Lacoste 2012, 19). La proximidad del objeto dista de la lejanía de su significado, que requiere un viaje experiencial del tipo que veremos más adelante.

12 Cfr. Palmer 2002, 127-156.

13 Cfr. Heidegger 2010.

Cfr. Gadamer 1977.

Cfr. Grondin 1999, 157-178.

Cfr. Beuchot 1999.

17 «Las botas campesinas las lleva la labradora cuando trabaja en el campo y sólo en ese momento son precisamente lo que son. Lo son tanto más cuanto menos piensa la labradora en sus botas durante su trabajo, cuando ni siquiera las mira ni las siente» (Heidegger 2001, 23). 
o transite por el sujeto para que éste último alcance una compresión del ente mismo y no de su imagen o re-presentación ${ }^{18}$.

\subsection{Modos de comprender II: ontologización hermenéutica}

La estructura de la ontologización de la hermenéutica es la base de una comprensión experiencial. Esta no se funda en la explicación sino que adquiere un carácter mostrativo, o descriptivo en terminología de Paul Ricoeur ${ }^{19}$, puesto que ayudar a otro a adquirir una visión de la realidad depende de ayudarle a que recorra su camino personal $^{20}$. Este acto le proporcionará una perspectiva propia del fenómeno sobre el que se centre en lugar de imponer la propia. La diversidad de interpretaciones sobre una misma religión reside en este fenómeno experiencial ${ }^{21}$.

Existen múltiples interpretaciones de cada religión hoy y en el pasado ${ }^{22}$. La contemporaneidad nos ha mostrado creyentes que usan el texto sagrado para perpetrar actos terroristas $^{23}$, mientras que otros aseveran que esa óptica constituye una deformación hermenéutica ajena a la correcta ${ }^{24}$. La identificación de la interpretación con la verdad agrava la situación, puesto que el diálogo no bascula sobre percepciones sino sobre la posesión de la auténtica verdad. Los horizontes pueden haberse separado tanto que el espectador externo puede tener la sensación de encontrarse ante dos religiones diferentes. El conflicto hermenéutico es obvio ${ }^{25}$ y reclama una urgente clarificación. De acuerdo con Armstrong, "cada fundamentalismo tiene su ley y su dinámica" (Armstrong 2009, 22), pero todos ellos coinciden en el trasvase de la importancia del mythos al logos: "Quizás hoy hemos perdido en Occidente el sentido del mythos, pero estamos muy familiarizados con el logos, que es la base de nuestra sociedad" (Armstrong 2009, 27)

Más allá de aclarar cuál es la correcta forma de ver el mundo, habría que indagar sobre cómo es posible que, partiendo de un texto común, se puedan generar visiones tan dispares que conduzcan a un conflicto que amenace la vida de los demás. Si se vislumbrasen las razones de la ineficacia ${ }^{26}$ del marco ideacional y se pudiera propo-

18 Entiéndase re-presentación como un modo indirecto de presentarse la realidad mediado por condiciones apriorísticas kantiana o por determinaciones culturales y de otra índole y, que por ende, dificultan la presentación inmediata del objeto.

19 Cfr. Ricoeur 2003, 289. Ricoeur define la hermenéutica en los siguientes términos: "la interpretación es el trabajo del pensamiento que consiste en descifrar el sentido oculto en el sentido aparente, en desplegar los niveles de significación implicados en la significación literal" (Ricoeur 2003, 17).

20 Este acontecimiento es la base del concepto de experiencia que desarrolla, entre otros, Claude Romano (Romano 2012, 212 y ss).

21 Claude Romano ha desarrollado el concepto de experiencia como lugar de aprehensión del acontecimiento por el sujeto. El lector interesado puede consultarlo en Lo posible y el acontecimiento (Romano 2008) y El acontecimiento y el mundo (Romano 2012).

22 Cfr. Llopis 2016.

23 Cfr. Korstanje 2015; 2013.

24 Como señala Armstrong, el fundamentalismo o es un hecho arcaico sino nuevo: "los extremistas religiosos jamás hecho un uso tan hábil de los medios modernos de comunicación como en el 11 de septiembre" (Cfr. Armstrong 2009, 15).

25 Armstrong asevera que "desde la perspectiva de un laico, estos ataques con motivación religiosa son incomprensibles" (p. 13).

26 Nótese que la esterilidad del diálogo no siempre es una realidad, puesto que muchos diálogos interreligiosos se basan en el contraste entre opiniones. Por ello, este artículo no pretende negar sus potencias sino completarlo con otro abordaje que enfrente aquellos casos donde el intercambio de opiniones sea infructuoso. La experiencialidad es, de facto, la base para que muchos diálogos basados en ideas rindan frutos, puesto que los interlocutores manifiestan una actitud de apertura inherente a aquel que ha vivido determinadas experiencias. 
ner otro en que se incentivase el entendimiento, se estarían dando los primeros pasos para resolver el conflicto.

\subsection{Abriendo el escenario: ideas y creencias. Correligionarios de creencias opuestas}

La clarificación de lo anterior se entiende recuperando las categorías orteguianas de ideas y creencias. «Las ideas, se tienen; en las creencias, se está » ${ }^{27}$ afirma el filósofo madrileño. Las ideas son ocurrencias mudables puesto que pertenecen al individuo, esto es, la persona ejerce un control consciente y eficaz sobre ellas ${ }^{28}$. De este modo, si alguna presenta debilidad ante un argumento nuevo o frente a una circunstancia que la invalida, el individuo la abandona. Así, un adolescente corrige en su memoria la fecha de la llegada de Colón a América o del propio peso leyendo un libro o subiéndose a la báscula, respectivamente. El análisis conceptual, el pensamiento crítico, la lógica formal y la informal son útiles en el intercambio de ideas puesto que su raíz es la racionalidad lógico-argumental.

Ahora bien, existe una distancia entre las ideas y la realidad personal que nos impide «vivir de ellas» ${ }^{29}$. Ésta es la razón de que se puedan modificar con relativa facilidad: si viviésemos de ellas, su transformación provocaría una crisis existencial de primer orden ${ }^{30}$.

Ítem más: «entre nosotros y nuestras ideas hay, pues, siempre una distancia infranqueable: la que va de lo real a lo imaginario». Sobre esta base, es posible defender ideas éticas que no guardan coherencia con la propia existencia, puesto que «nuestra idea de la realidad no es nuestra realidad» ${ }^{31}$. Así, se explicaría el hecho de un profesor de ética (1) erudito en su materia (2) se entregue a actos ejemplares de la mayor maldad. Si las ideas no cumplen esta función fundamentadora de la existencia, ¿cuál es la base de la existencia, el asidero, aquello que protege de la duda o de la falta de certidumbre? ¿De dónde emerge la determinación de nuestras decisiones o dónde se asientan nuestros afectos, sentimientos e inclusive nuestras ideas? La respuesta orteguiana apunta aquí a las creencias.

Las creencias son «ideas que somos», «constituyen la base de nuestra vida, el terreno sobre que acontece», vivimos «de ellas». «Con nuestras creencias estamos inseparablemente unidos. Por eso, cabe decir que las somos. Frente a nuestras concepciones, gozamos un margen, mayor o menor, de independencia». Las creencias se plantean como el «contenedor» de nuestra vida y, por ende, de nuestras ideas ${ }^{32}$.

Regresando al tema de este trabajo, podríamos pensar que la creencia es la versión del Islam o del Catolicismo que se defiende, pues conforma el «continente» que moldea la fe. En terminología aristotélica, la religión como idea sería la causa material, la religión como creencia las causas formales, finales y eficientes.

Imaginemos dos recipientes (creencias): una vasija de acero calentada más de quinientos grados Celsius y un bloque de hielo enfriado a quinientos grados bajo cero. Cuando vertemos en ellos agua de la religión (idea), el producto obtenido (el

\footnotetext{
Ortega y Gasset 1994, 383-384.

Cfr. Bolado 2014, 87-135.

Ortega y Gasset 1994, 384.

Cfr. Curnow 2016, 42-43.

Curnow 2016, 388.

Cfr. Curnow 2016, 384.
} 
creyente) es diferente. En uno, el agua (creyente) se evaporará; el otro solidifica el líquido en otro bloque de hielo que proyectado de la forma adecuada puede provocar la muerte. En ambos casos, el agua (idea) es idéntica, $\mathrm{H}_{2} \mathrm{O}$, pero la forma obtenida (creyente) debido a su recipiente (creencia) es diferente. Análogamente, sucede con las religiones de aquel creyente que ha vivido su fe en periodo de paz y la de quien ha sido motivo de cruentas luchas. En síntesis, la religión, una para todos los fieles del mismo credo, se colorea creencialmente con tintes fanáticos, violentos, pacíficos, intolerantes, indiferentes u otros de acuerdo con cada experiencia. La creencia del fanático terrorista priorizaría unos principios transcendentales que legitiman el atentado, actitud incongruente para un correligionario con idéntica religión, pero diferente creencia. En suma, la creencia determina el modelo de religión practicada.

\subsection{La dificultad de disolver las creencias}

Siguiendo un itinerario práctico, una vez explicado el universo donde se instalan las creencias, habría de mirar a la razón de la dificultad para disolverlas o para crear otras nuevas. Ortega lo explica con claridad meridiana

Las creencias constituyen la base de nuestra vida, el terreno sobre que acontece. Porque ellas nos ponen delante lo que para nosotros es la realidad misma. Toda nuestra conducta, incluso la intelectual, depende de cuál sea el sistema de nuestras creencias auténticas. En ellas «vivimos, nos movemos y somos». Por lo mismo, no solemos tener conciencia expresa de ellas, no las pensamos, sino que actúan latentes, como implicaciones de cuanto expresamente hacemos o pensamos. Cuando creemos de verdad en una cosa no tenemos la «idea» de esa cosa, sino que simplemente $«$ contamos con ella $»^{33}$

En primer lugar, la creencia es una realidad con la que contamos, es decir, no solemos criticar sus contenidos sino que se alza sin mediaciones como base de la propia existencia. Abarca desde la fe en una religión, hasta la confianza en la fidelidad de nuestra pareja o la certidumbre de que ningún avión se estrellará contra la tercera planta de la biblioteca Lamont de Harvard o de que cuando coja el metro al Retiro no existirá ninguna mochila con dispositivos explosivos en el vagón. Al contar con creencias que proporcionan esta confianza, es posible vivir con el amparo suficiente para realizar cada actividad de la vida: acabar un artículo, evitar la intranquilidad de ser traicionado por la pareja o de tomar el metro sin plantear la alternativa de un taxi, un autobús o, sencillamente, ir a pie. En consecuencia, la creencia posee un valor adaptativo de primer orden al suministrar una realidad equilibrada sobre la que construir ideas, sentimientos, valores y modos de ver la realidad.

Más allá de la creencia, amenaza la crisis ${ }^{34}$ : si una creencia se desploma, no sólo muta una idea, o un conjunto de ellas, sino que queda abatida la realidad que ésta alza, se abdica del propio ser, la identidad sobre la que se yerguen las dimensiones de la existencia personal. En la crisis, las creencias abandonan extravían su función adaptativa y, por ende, se desmorona la propia vida: se entra en «un mar de dudas» ${ }^{35}$

\footnotetext{
Curnow 2016, 387-388.

Cfr. Curnow 2016, 392-394.

Curnow 2016, 392.
} 
o se vive en «inquietud» $»^{36}$. La crisis provocada por la testificación de la infidelidad conduce a la abandonar esa existencia que creía en el amor sin fisuras y la generada por el atentado en el metro la inquietud que obliga a replantearse la eficacia de los cuerpos de seguridad del estado. No sólo se crea un sentimiento de desasosiego inédito sino que la toma de decisiones y las cosmovisiones se transformarán.

La seguridad de las creencias conjura las posibilidades (y capacidades) metamórficas, se vive en la zona de confort. La defensa de las creencias es contigua a la de la propia persona (o el personaje deudor de esa creencia). La inquietud, la angustia y la eventualidad del extravío existencial no son regalos bien recibidos por el común de los mortales. Ahora bien, esta situación se convierte en obcecación y raíz de ceguera como sucede cuando no se desea ser consciente de la infidelidad de la pareja a pesar de los indicios o cuando uno «no quiere creerse» la realidad de los atentados del 11-S de Nueva York, los de Madrid de $2004^{37}$, los de Boston de $2013^{38}$ o los de Bruselas de 2016.

Ítem más: la quiebra de la creencia es un proceso doloroso. Implica un duelo por la muerte no sólo de ésta sino del personaje creado. Se percibe con amargura el engaño del personaje anterior no porque lo sea en términos genéricos sino porque lo es desde el contexto de las nuevas coordenadas. El converso no se reconocerá en su yo pasado, e incluso, en un acto de última defensa, puede culpabilizar de sus decisiones a un fraude bien orquestado de agentes externos.

Por otro lado, su ausencia de certidumbres le conmina a ejercer la heroicidad de orquestar nuevas bases sobre las que edificar la nueva identidad y su artesonado creencial. Se habrá de articular modos para recuperar la confianza en el mundo so peligro de desarrollar comportamientos disfuncionales como quedar encerrado en el propio domicilio o guardar un celibato aterrorizado por una nueva deslealtad afectiva.

La reiteración de las crisis encauza dos cursos de actitudes vitales: el descreimiento (la postura escéptica y/o cínica de quien se duele en su pena y en su desconfianza del mundo proyectando en él la culpa) o la humildad (la actitud de aceptar la caída, abductivamente, y la propia limitación). El descreimiento apunta a dos líneas un sujeto que todavía se cree como el artífice de la nueva solución ${ }^{39} \mathrm{o}$ la amargura de evidenciar sus limitaciones para ofrecer una respuesta definitiva. Por el contrario, la humildad desplaza las posibilidades poiéticas hacia el objeto: la nueva persona no se intelige como algo construido sino recibido, aquí, la palabra es sustituida por el silencio y el habla por la escucha. Esta humildad no se determina pasivamente; exige la preparación para despejar el camino y para que el objeto se revele, pero no impone el propio esquema que, en última instancia, acabaría en una nueva crisis y reconstrucción.

Esta explicación de la entraña de la idea y de la creencia aclara la futilidad de muchos esfuerzos dialógicos basados en la transformación de las ideas y no de las creencias. Ahora bien, quedaría pendiente saber si existe alguna forma de actuar sobre los contenedores creenciales con la misma eficacia que el pensamiento crítico

\footnotetext{
Zambrano 2004, 100.

Cfr. Avilés 2015; Navarro 2014.

Cfr. Israel - Pomares 2015.

Ésta es la crítica que Zambrano hace sobre Europa. Si España es la aceptación de la caída, Europa es aquella que, ante la evidencia de su fracaso, genera una y otra vez la ilusión ideológica de volver a intentar una salida por vías diferentes (Zambrano 1996b, 2000). En ese sentido, la malagueña asevera que «no se puede morir Europa porque tiene que proseguir el camino, que es agonía, que es calvario de la esperanza desatada. Y tendrá que seguir pariendo, pariéndose a sí misma, en la historia» (Zambrano 1989, 244)
} 
opera sobre las ideas. La respuesta obliga a ser conscientes de cómo se gestan los compendios creenciales y cómo se ponen en crisis. La educación, los hechos históricos de la propia cultura o la psicología contribuyen a estos cambios; no obstante, todos ellos mantienen un nudo gordiano metamórfico común: la experiencia.

\section{La experiencia}

\subsection{El viaje experiencial}

En alemán, «Erfarhung» significa «experiencia»; su verbo es «fahren», que equivale a «viajar» o «navegar». Toda experiencia es una navegación, un periplo (o una travesía según Romano ${ }^{40}$ ), donde, siguiendo el poema de Cavafis, lo crucial no es el destino sino la metamorfosis producida por la vivencia de los acontecimientos que suceden en él.

Dado lo anterior, resulta complicado afirmar que el recorrido del empresario que toma el NJTransit diariamente para ir desde Dover a Penn Station o que coge el AVE para desplazarse de Sevilla a Madrid sea una auténtica experiencia, aunque no se niega su condición de traslado físico. Distinta es la odisea de Ulises o la de Néstor, uno de los argonautas. El empresario no manifiesta cambio identitario alguno; de hecho, se acostumbra a utilizar estos «tiempos muertos» en el tren para dormir (fenómeno por antonomasia de desconexión) o para acabar algún trabajo en su ordenador (evitando la posibilidad de la experiencia y de la aventura metamórfica, a saber, contactos con personas, paisajes o circunstancias nuevas. Cuando Ulises o Néstor regresan de su travesía han adquirido una nueva forma de ver la realidad, el hecho de haberse tenido que enfrentar a sus propios límites y miedos le obliga a adquirir un nuevo rostro que trastoca todas sus dimensiones ${ }^{41}$.

Los cambios no son neutros sino que rinden beneficios para el sujeto que acaba siendo más profundo y desarrollando una mayor sutileza o agudeza para intuir grosores en la vida que «el común de los mortales» no atisba al estar entre-tenidos (o tenidos en el entre) con las cuitas y urgencias propias de la fugacidad diaria ${ }^{42}$.

La adquisición del rostro propio exige exponerse a riesgos como señala la etimología de la experiencia: su raíz, «per», ha sido vinculada con «perigro» ${ }^{43}$. De hecho, el sujeto asiste a la mayor amenaza ${ }^{44}$ : la pérdida del sí mismo, de su ser pasado, pues no hay nuevo sujeto sin abandono del anterior. En suma, la experiencia inaugura una nueva vida ${ }^{45}$, pero se construye sobre un acto funerario previo.

$40 \quad$ Cfr. Romano 2012, 214-216.

41 A pesar del argumento esgrimido, el viaje en AVE o en el NJTransit se convertiría en una experiencia si acarrean un cambio existencial análogo al de los héroes. Ése sería el caso si se produjese un descarrilamiento donde se salvase milagrosamente la vida o si es el tren en el que se conoce al amor de la vida.

42 Nótese que una mirada atenta a esas cuitas también podría ayudar a una transformación experiencial como ha indicado Josep María Esquirol en su filosofía de la proximidad (Esquirol 2006; 2015). El concepto ha sido desarrollado excepcionalmente dentro de la tradición confuciana por Javier Bustamante (Bustamante 2016, 60-63).

43 Ortega y Gasset 1994, 176.

44 Ese riesgo se dirige a lo más nodal del sujeto. En palabras de Romano: "La experiencia consiste en ese riesgo de una exposición a lo que me alcanza en pleno corazón: al acontecimiento" (Romano 2012, 214).

45 Este inicio se dará sólo una vez puesto que la experiencia "es la sensación absolutamente única de lo que no se verá por segunda vez” (Romano 2012, 216). No obstante, diversas experiencias inaugurarían diferentes modos identitarios de ser 
Ortega apunta una segunda conexión de «per»: «portus» o «puerta». No hay experiencia sin atravesar puertas de un solo sentido. Los ritos de paso dejan constancia de esta circunstancia de forma elocuente. Diversas tribus obligan al joven a enfrentarse a circunstancias que marcaban al individuo por el resto de sus días. Aunque muchas de estas marcas y ritos no se corresponden con el espíritu de la experiencia puesto que más que crear posibilidades en el sujeto las cierran, otras, a pesar del peligro obligan al sujeto a adquirir el rostro de adulto. Enfrentarse a una fiera y regresar con su cabeza como trofeo y símbolo; realizar un camino iniciático e incluso el paso por el servicio militar marcaba ese tránsito: allí, el niño se hacía hombre y había de aprender a partir de los padecimientos y de la ausencia de la seguridad del hogar familiar cómo enfrentar la vida.

La anagogía es la forma comprensiva propia la experiencia. La anagogía consiste en comprender contenidos, densidades o grosores de la realidad después de haber padecido ciertas experiencias ${ }^{46}$, no siendo suficiente la explicación teórica. La aprehensión del significado profundo de la maternidad sólo se genera en quien ha dado a luz y ha vivido de forma consciente el proceso de crianza; el amor se entenderá después de haberlo vivido en carne propia circunstancias alegres, dolorosas, dificultades y éxitos junto al ser querido. Esto es debido a que la experiencia genera no sólo la metodología de comprensión ${ }^{47}$ sino la citada nueva identidad que es el único prontuario desde el que se puede comprender ciertos contenidos. En síntesis, sólo la joven que se convierte en madre comprende un sentido profundo de la maternidad y sólo quien el amante es capaz de comprender la experiencia del amor ${ }^{48}$.

De acuerdo con Nishida, «experimentar significa conocer hechos tales como éstos son, conocer en conformidad con hechos renunciando por completo a las propias elaboraciones $\rangle^{49}$. En la medida en que la experiencia no es una interpretación subjetiva de lo que se vive $e^{50}$, la anagogía no produce un conocimiento limitado por el propio espacio y tiempo: el sujeto no crea la experiencia sino que entra en ella, ésta no es una posesión de él sino que él entra a formar parte de ella. En palabras del japonés, «no hay experiencia porque exista un individuo sino que existe un individuo porque hay experiencia» ${ }^{51}$.

El conocimiento anagógico-experiencial pasa de ser una aprensión intelectual a una inmersión directa de la realidad directa realizada por todas las dimensiones de la persona y no sólo por la cognitiva ${ }^{52}$. Zubiri refiere que la experiencia es una «proba-

46 Cfr. Antón Pacheco 2010, 72-73.

47 Ricoeur destaca que "la ontología de la comprensión está implicada en la metodología de la comprensión" (Ricoeur 2003, 23), es decir que para comprender algo hay que recorrer un camino que es el que nos desvela cómo hay que acceder a ello. En este trayecto hay que realizar ejercicios ascéticos: "practicar una verdadera ascesis de la subjetividad (...) una pérdida real del más arcaico de todos los objetos: el yo"(Ricoeur 2003, 24)

48 Esto no quiere decir que no pueda comprenderse la maternidad desde otras perspectivas, pero hay algo irreductible en la experiencia de ser madre que facilita este conocimiento entendido desde la atalaya experiencial.

49 Nishida $1995,41$.

50 Cfr. Castro 2015.

$51 \quad$ Nishida $1995,59$.

52 De hecho, la comprensión cognitiva puede llegar a dificultar la comprensión del objeto, tal y como sugiere Ricoeur: "La tarea de la filosofía a partir de aquí. ¿no es acaso la de reabrir sin cesar, hacia el ser dicho ese discurso que, por necesidad de método, la lingüística no cesa de clausurar en el universo cerrado de los signos y en el juego puramente internos de las relaciones mutuas?” (Ricoeur 2003, 74). Esto se puede ver cuando se analiza el mal (Ricoeur 2003, 281) o el símbolo: "Opacidad, contingencia cultural, dependencia respecto de un desciframiento problemático: son las tres deficiencias del símbolo, frente al ideal de claridad, de necesidad y de cientificidad de la reflexión" (Ricoeur 2003, 289). 
ción física de la realidad ${ }^{53}$ y para Nishida en la comprensión experiencial «no existen brechas entre las demandas de la voluntad y su realización» ${ }^{54}$, porque en la «experiencia pura sujeto y objeto están unidos ${ }^{55}$ :

En el momento de la experiencia pura, no hay todavía ninguna oposición de sujeto y objeto, ni separación de conocimiento, sentimiento y volición; sólo existe una actividad pura, independiente, autosuficiente ${ }^{56}$

\subsection{El producto cognoscitivo de la experiencia: la evidencia}

Si el producto del pensamiento crítico y del análisis conceptual es la idea, la experiencia proporciona evidencias.

La cristalización de la evidencia es lenta y responde a un proceso (viaje) donde se van escanciando posos. Estos se compactan por el peso que le es inherente hasta que llega un día en que rutilan con una nueva luz, sucediendo lo mismo que el día en que el grafito se convierte en diamante. Ítem más: la evidencia nace en los instantes de iluminación en los que el individuo ve (nótese la raíz que tiene la palabra evidencia en relación al sentido de la vista). Un sujeto puede haber escuchado decenas de veces una frase; sin embargo, la comprensión experiencial se produce en el momento en que el individuo «ve» su sentido con una claridad suficiente para generar certidumbre y fundamente a la propia vida.

De acuerdo con María Zambrano, la evidencia es «terriblemente pobre en contenido intelectual» ${ }^{57}$. Sus verdades, como las del poeta o la del sabio, transparentan un contenido del que puede llegar a mofarse el intelectual, puesto que su potencia no reside en la corrección lógica de su estructura o en lo bien armado que se encuentre su argumento sino en la capacidad fecunda y metamórfica que manifieste ante quien es capaz de escucharla y en la posibilidad de ayudar a recuperar la certidumbre a quien la perdió.

Por eso el dicho de la sabiduría es tan pobre en su enunciado, y parece decepcionante, pero no deja de dar que pensar, porque en su banalidad llana se acerca al plano fundamental (igual) que hace que todo comunique ${ }^{58}$

$\mathrm{Su}$ vigor es descrito con claridad en el concepto de acontecimiento que Romano recupera del Ereignis Heidegger. Merece la pena detenerse en él, puesto que no sólo lo describe sino que lo ejemplifica con el caso de quien presencia la muerte de un ser querido:

El acontecimiento no se reduce de ninguna forma a su actualización como hecho; desborda todo hecho y toda actualización por la carga de posibles que mantiene en reserva y en virtud de la cual lo que toca son los cimientos mismos del mundo para el existente. No realiza solamente un posible previo, pre-esbozado en el

\footnotetext{
Zubiri 1984, 95.

Nishida 1995, 46.

Nishida 1995, 67.

Nishida 1995, 90.

Zambrano 1995, 69.

Julien 2001, 212.
} 
horizonte de nuestro mundo circundante; alcanza lo posible en su raíz y, por consiguiente, trastorna el mundo entero de aquel a quien sobreviene: no es tal o cual posible, es la 'cara de lo posible', la 'cara del mundo' que aparece para él cambiada. O, para decirlo de otro modo, un acontecimiento no modifica solamente ciertas posibilidades en el interior de un horizonte mundano que permanecería, como tal, incambiado; al trastornar ciertos posibles, reconfigura, en realidad, lo posible en su totalidad. Proust lo dice admirablemente a propósito de la muerte de Albertina: lo que vacila con esta muerte, no son solamente todos estos posibles 'vinculados a ella', los proyectos, los gustos comunes, las costumbres, el arreglo de ciertos lugares, la naturaleza de algunos placeres; sino que son la sensibilidad misma de los seres y las cosas, la manera de relacionarse con la vida social, con el arte, con la misma muerte los que aparecen en adelante bajo una luz diferente (Romano 2008, 42-43)

Afirmaciones sabias como «sólo el agua sabe horadar la roca», «escucha tus pasiones y huye de tus emociones porque las primeras te mantienen en el camino y las segundas te detienen en la pasividad», «quien busca soledad acaba encontrándola» o «mejor verdes que podridos», o refranes como «quien a buen árbol se arrima, buena sombra del cobija», «a quien madruga, Dios le ayuda» o «quien bien te quiere te hará llorar» ${ }^{59}$ parecen banales, pero que, como señala Julien, dan que pensar, conectan con verdades profundas sobre las que se instala la vida y, todavía más, pueden convertirse en parte del maderamen creencial del sujeto ${ }^{60}$. Repitámoslo, la eficacia del aserto experiencial, de la evidencia, no se mide por el peso lógico del argumento sino por la potencia de su elocuencia para fraguar asideros con los que vivir. Esos agarres, no lo perdamos de vista, eran sobre los que el creyente alzaba sus ideas.

La evidencia asume el círculo hermenéutico que vincula parte y todo (la parte trasluce el todo y el todo se intuye en cada parte) debido a que su acceso a la realidad es holístico. Comprender la experiencia de la maternidad no precisa haber pasado por cada modalidad de ser madre: es suficiente haber vivido en profundidad una de ellas para lograr una comprensión integral de su sentido.

Hemos estudiado el modelo de la experiencia en cuatro campos: sabiduría, estética, mística y filosofía. Todos ellos poseen características que aclaran el concepto. Aunque éste no es el lugar de ampliar esta cuestión, avanzamos algunas características que facilitan la aprehensión experiencial: humildad ${ }^{61}$, apertura ${ }^{62}$, coraje, retiro

59 El saber experiencial es inherente a otros géneros literarios como las exhortaciones de padres a hijos, del señor a su esclavo, la literatura sapiencial, las parábolas (Balthes inédito; Curnow 2010) e incluso se encuentra en situaciones del diario vivir como la siguiente contada por Walter Benjamin: «En nuestros libros de cuentos está la fábula del anciano que en su lecho de muerte hace saber a sus hijos que en su viña hay un tesoro escondido. Sólo tienen que cavar. Cavaron, pero ni rastro del tesoro. Sin embargo, cuando llega el otoño, la viña aporta como ninguna otra en toda la región. Entonces, se dan cuenta de que el padre les legó una experiencia: la bendición no está en el oro sino en la laboriosidad» (Benjamin 1973, 167). La afirmación «la bendición no está en el oro sino en la laboriosidad» podría ser rebatida con el poder gimnástico de un académico; aun así, constituye una verdad profunda en sí misma lo cual se comprende si se interpreta no desde su superficie sino desde el fondo desde el que se proclama, lugar que dejamos al lector descubrir.

60 El saber o conocimiento intelectual o cognitivo no alcanza a saborear como el evidencial ni a comprender objetos que son demasiado amplios para sus miras humanas. Por eso, Lacoste llega a afirmar que "el saber [cognitivo] consagra la distancia que nos separa de una fruición definitiva de lo Absoluto" (Lacoste 2012, 188).

$61 \quad$ Cfr. Krause 2016.

$62 \quad C f r$. Spiegel 2012, 27-38. 
asociativo $^{63}$, paciencia, desarrollo de la agudeza o sutileza para escuchar ritmos del tiempo, de los espacios, de las personas o de las situaciones, entre otras ${ }^{64}$.

La mayor parte de los conflictos religiosos emanan de sujetos que han realizado un viaje experienciales con evidencias específicas. Estas evidencias conforman la malla creencial desde la que toman decisiones, desde las que perciben el mundo o desde las que lo interpretan y, por ende, provocan verse afectados por él en una dirección u otra. En la medida en que el contenido de la experiencia no es una interpretación subjetiva sino una peregrinación hacia una objetividad liderada por el objeto, un auténtico camino experiencial privilegia la escucha de lo exterior sobre la imposición del propio diálogo. En consecuencia, el entendimiento en este contexto no perseguirá que el otro se avenga a mis evidencias puesto que esta demanda exigiría un poder de la subjetividad que no es propio de nuestro concepto. La vía correcta es la del camino común ayudados por la corrección mutua que extrae de las limitaciones espacio temporales de cada sujeto.

\section{Conclusión y camino: la mudanza de las creencias en la comun(icac)ión}

\subsection{Los problemas con la definición y con la palabra instrumental o no invocadora}

La definición proporciona visiones parciales del objeto al articular descripciones subjetivas de los fenómenos. El término (definir) comprende poner límites finitos a la realidad para separar de la totalidad. Esos límites conllevan un punto de partida subjetivo y, por ende, una selección de la realidad. De esta forma, incluso un mismo fenómeno como la maternidad se define de forma distinta para el psicólogo, el sociólogo o el ginecólogo. La visión de la maternidad desde sí misma, por así decir, sólo una definición de la maternidad dándose a sí misma, evitaría esta pluridimensionalidad relativista.

La exigencia de palabras como instrumento básico de la definición implica otra dificultad. Esas palabras no poseen un valor ontológico sino uno de cambio ${ }^{65}$. Esta circunstancia ha conducido a que ciertos autores defiendan la incomunicabilidad de la experiencia por medio de palabras ${ }^{66}$. Aún más, como la palabra se insertaría en un lenguaje específico, éste se alza ya como un medio a la vez capacitador y limitador para exponer contenidos experienciales.

Si la experiencia es incomunicable mediante palabras, ¿cómo sería posible llegar a un acuerdo y diálogo entre dos personas que hayan vivido experiencias distintas?

63 Cfr. Comte-Sponville, 2000, 29.

64 Cfr. José Barrientos Rastrojo 2011; 2015.

65 Este valor de cambio desaparece en el caso de ciertos juegos de lenguajes y géneros literarios como la poesía o el rito. Ahí, la palabra no sirve para apuntar a una realidad de la que se distingue y se distancia sino para invocarla. Esa invocación es posible porque la palabra posee en su seno peso ontológico, es realidad misma. En este sentido, el rito eucarístico no es la descripción del pasado sino la invocación de una realidad que se vuelve a actualizar por medio del ministro que pronuncia las palabras oportunas.

66 Es el caso de Panikkar (Panikkar 2001). A pesar de que aceptamos la limitación de la palabra instrumental para rescatar la esencia de la realidad, consideramos que ciertas modalidades de palabras (como la invocadora) servirían para traer los entes a superficie y, en consecuencia, para que pudieran transmitirse su contenido. 
¿Cómo se pueden comunicar dos individuos en relación a sus experiencias a la base de esta dificultad expresiva? ${ }^{67}$

Si la religión se fragua sobre la base de creencias, las creencias dependen de experiencias y las experiencias son incomunicables, queda clara la improductividad del diálogo cognitivo (basado en palabras instrumentales y subjetivas) en el campo religioso (o creencial). Ahora bien, ¿esta incomunicabilidad nos condena a un impasse donde sólo es posible el silencio y, por tanto, la renuncia a que podamos entendernos en el conflicto religioso?

Afortunadamente, la respuesta no ha de ser afirmativa: si se acude al proceso de formación de las creencias, se vislumbra que, igual que se contemplan diversas modalidades de palabras (una de ella es experiencial), las habrá de transmisión de contenidos. La experiencia propone un modo de comunicación no basado en la definición ni en la palabra transmisora instrumental sino en una dinámica donde la comunicación se transforma en comunión.

\subsection{De la comunicación a la comunión I: la relación}

Partamos de la comunicación como un proceso (eficaz aunque, en ocasiones, no suficiente) por el que un sujeto o grupo transmite a otro/s un conjunto de informaciones desde la perspectiva del emisor y utilizando habitualmente una palabra instrumental.

La comunión que aquí defendemos implica la conexión sin mediaciones entre dos interlocutores liderados por la aprehensión de una verdad que se facilita mediante la comunicación, pero cuyo fin descansa más allá de la interlocución ${ }^{68}$. A continuación, resumimos algunas características de la comunión comunicativa.

En primer lugar, la relación no se funda en la bidireccionalidad horizontal, inherente al intercambio intersubjetivo o intergrupal de la comunicación, sino en la verticalidad de profundización. La verdad no se obtiene del intercambio de perspectivas de la realidad sino de cómo esa conversación se encamina hacia una compresión guiada por el objeto de aprendizaje. De esta forma, se sale del subjetivismo al objetivismo liderado por la experiencia. En lugar de conversar sobre cuál es la visión adecuada de la religión (los recipientes creenciales aludidos páginas atrás), la comun(icac)ión dirigiría a los interlocutores al camino de la verdad. Por tanto, será crucial la escucha del otro y de lo otro (para corregir el propio error o limitación) que la imposición de la propia aproximación (limitada por las condiciones apriorísticas de un conocimiento subjetivo). Así, el contacto con el otro no debe desinstalarlo de su óptica ni destruir sus argumentos, puesto que la potencia de su diferencia permite salir de las fronteras propias. Ocioso es indicar que la afirmación inversa queda defendida también aquí.

El saber obtenido no se mide (1a) cuantitativamente por (2a) la cantidad de información del argumento sino (1b) cualitativamente por (2b) el nivel de profundidad

67 Todavía más grave, ¿cómo podría la palabra alcanzar sentidos trascendentales que exceden la limitación espacio-temporal del sujeto? Este tema ha sido desarrollado entre otros por Ladrière en La articulación del sentido (Ladrière 2001). Martín Velasco indaga en esta cuestión por medio de la inabarcabilidad humana del Misterio: "lo propio del Misterio es designar una realidad de la que el hombre no puede hacerse cargo en absoluto" (Martín Velasco 2006, 113).

68 Curiosamente, la comprensión de ciertas creencias exigen el desarrollo de la comunidad, siendo habitual en el caso de la religión: "La historia de las religiones constata como un hecho constante la cristalización de la actitud religiosa del sujeto en una magnitud social" (Martín Velasco 2006, 166). 
que procura al sujeto $^{69}$. El conocimiento pasa de ser una cuestión epistémica a ontológica u antropológica, como sucedía en el paso de la palabra instrumental a la vocativa. Decíamos con Zambrano que la evidencia podía ser terriblemente pobre en contenido, sin embargo, su valor reside en su potencial transformador; éste depende de la potencia ontológica que tenga sobre la realidad y de la capacidad para cambiarnos en alguien con capacidad para ver con sutileza realidades que no están al alcance de todos.

El conocimiento se convierte, ante todo, en reconocimiento. Debido a las capacidades intuitivas despertadas, y al igual que todo sabio es acreedor de respeto y alabanza, quien conoce en los términos aquí descritos va adquiriendo una identidad cada vez más digna de elogio. Asimismo, el reconocimiento apunta a un saber experiencial consistente en volver a acceder a (volver a conocer) contenidos que se suponía dominados, pero que no se habían evidenciado. Esta es la circunstancia que vive quien, después de padecer ciertas experiencias, reconoce «¡cuánta razón tenían mis padres!». En esa frase se sintetiza un saber nuevo (experiencial) de algo previamente conocido.

El reconocimiento consiste en el tipo de relación que se fragua entre dos sujetos o grupos que descubren que el otro ha materializado el mismo viaje experiencial que uno mismo. Así, la mirada cómplice de dos terroristas, el modo de verse afectados por fenómenos externos, la forma de afrontar los problemas o su ideas permiten que se reconozcan entre ellos como miembros de una comunidad no construida por ellos sino en la que sus experiencias los insertan. Las consecuencias de este último ejemplo son dignas de reseñar. Parte de la motivación de los atentados nace a partir de una pérdida violenta e injusta de familiares muy próximos y la impotencia ante el agresor. Esa circunstancia dota de evidencias que, como aseverábamos, afecta a todas las dimensiones humanas. Si esta circunstancia se sobregeneraliza y se vincula experiencialmente a una cruzada de dimensiones globales, notamos la exigüidad de la palabra para desarticular sus ideas ${ }^{70}$.

\subsection{De la comunicación a la comunión II: la palabra invocadora}

La comunión como comunicación reclama el uso sustancial e invocador de la palabra. La palabra se ha utilizado, con frecuencia, como mera transmisora de contenidos, es decir, ha sido prostituida al imponérsele un reductor valor de cambio en lugar de permitir que se abra su significado propio. La palabra invocadora no explica sino que traslada al sujeto a la realidad o reifica el mundo, es decir, lo trae sin mediaciones. Avanzamos que esto era propio de palabras en contextos como la poesía ${ }^{71}$, la estética, la sabiduría o la mística. Si la palabra instrumental es sustituible, es decir, la definición de un concepto puede ofrecerse usando sinónimos, no cabe tal proceso en

69 La vivencia del día a día es cuantitativa, pero la experiencia creencial es cualitativa, el problema, como señala Lacoste es que "esta experiencia originaria es recusada constante y vivamente por la experiencia cotidiana" (Lacoste 2012, 23)

70 Si la experiencialidad se lleva a la educación, es decir, si se aboga por una educación experiencial sin entrar en los contenidos, ¿no se corre el riesgo de que pueda usarse con fines terroristas? Nuestra respuesta es negativa puesto que una característica básica de la experiencia es la apertura a la alteridad plural y no la clausura inherente a quien asesina.

71 De hecho, las relaciones entre poesía y sutileza han sido estudiadas por diversos autores. Entre los textos más cercanos a nuestros días podríamos citar a Antonio Heredia (Heredia 2014, 23) 
la palabra invocadora: cada palabra invocadora abre un mundo diferente. Su configuración se podría comparar con el de la música: si en una frase musical o en una sinfonía se cambia una nota, ¿no se distorsiona el sentido completo de la sintonía? Cada nota contribuye a la invocación total y entre las notas musicales no es posible hablar de notas sinonímicas.

A la vista de lo anterior, la comun(icac)ión tendrá un especial cuidado con los silencios, el ritmo (y también con el gesto ${ }^{72}$ ): todos ellos poseen una energía expresiva de análoga elocuencia a la palabra invocadora. Por consiguiente, el acrecentamiento de la sutileza para comprender el discurso de la comunidad (integrado por estos elementos) es básico. Atender a las palabras y descuidar o menospreciar el ritmo, la musicalidad, la cadencia o el peso y color de cada palabra puede ser el principio de la contienda. De aquí, también, que la palabra pueda convertirse en un arma o un proyectil si se lanza con la suficiente habilidad invocativa.

Esta idea es rescatada por Habermas cuando señala que la cooperación no se explica desde la "coacción a la cooperación" (p. 14) sino sobre una sintonía en valores y expectativas de comportamiento. Este proceso se da a través de gestos e incluso de movimientos corporales que podrían estar en el ámbito de una religión (ritos) o de la estética (apela aquí a la danza), o incluso una "danza ritual" que "favorecen una asunción mutua de perspectivas" (Habermas 2015, 63) "73:

Los implicados entablan, «en virtud de»o «gracias a» movimientos corporales generados intencionalmente, una relación comunicativa y se refieren conjuntamente a causa de esos gestos al mismo hecho (...). El elemento material, el sonido o el movimiento corporal, provoca, como un catalizador (...) Llegan a generar shared intentions, es decir, percepción e intenciones compartidas (Habermas 2015, 57)

La invocación en la palabra explica su metamorfosis desde el universo de la transmisión de información a un mundo donde se convierte en porteadora o transportadora del sujeto. María Zambrano nos proporciona un ejemplo expresivo en Horizontes del liberalismo. El nacimiento de la ética deontológica puede explicarse, con palabras transmisoras, relatando el origen de esta ética en Kant, refiriéndonos a fechas o contenidos, tal como acostumbran a hacer libros y clases informativas desapasionadas. Sin embargo, hay otra forma de explicar el nacimiento de esa ética: usando la palabra para crear (o invocar) el universo en el que se creó esa ética. Así lo hace Zambrano:

Anfibios instantes de epiléptico temblor; en que giraban, mezcladas, todas las pasiones que encierra en los hondos subterráneos de su recinto el corazón humano. Turbias apetencias de un orden nuevo. Ansias obscuras de una luz que se columbraba lejana $^{74}$

72 Cfr. Esquirol 2015.

73 La vinculación entre arte y religión resulta obvia para Habermas, quien subraya que se produjo un "proceso de lingüistización de lo sagrado" (Habermas 2015, 19). De hecho, "las formas de expresión estéticas y altamente desarrolladas -como la música, la danza y la pantomima, la pintura y la escultura, incluidas las resonancias onomatopéyicas, sin las cuales no es posible entenderla literatura, sobre todo la fuerza evocadora de los poemas-, siguen estando arraigadas en una comunicación simbólica pero no verbal" (Habermas 2015, 69).

74 Zambrano 1996a, 240. 
Se podría explicar el texto con términos instrumentales: indicar que ese cambio ético supuso un momento de transición como si de la vida de un anfibio se tratase, esclarecer que se atestiguan momentos de miedos y temblores de una pujanza inaudita, aquella que aparece en una crisis epiléptica que puede llevar a la muerte de quien la sufra. En ese minuto germinal, se puede añadir, todo gira y está mezclado porque no hay claridad de hacia dónde se discurre; es más, esa confusión se da en los lugares de mayor lobreguez, las pasiones de los subterráneos del corazón. A pesar de ello, hay un anhelo por descubrir la novedad: «turbias apetencias de un orden nuevo». En esta línea, aparece una imagen elocuente, la de una luz remota que se persigue con una sed inusual, esa luz es la de la ética deontológica. Sin embargo, la experiencialidad comunicativa del texto no reside en esta explicación sino en su capacidad para trasladarnos a ese nacimiento, esto es, permitiéndonos percibir cada una de las imágenes en el propio interior o sintiéndonos rodeados por la experiencia como si se diera físicamente.

Este uso de la palabra facilita que el aprendizaje anagógico, inherente a la experiencialidad y a la comun(icac)ión no siempre requiere una experiencia directa, sino que la experiencia indirecta de una narración con palabras ontológicas o de una obra de arte rinde los mismos resultados. Cuando el héroe regresaba y contaba la historia a los jóvenes les proporcionaba un conocimiento que iba facilitando la entrada de la comunidad de los que saben. La palabra no sólo comunicaba contenidos sino que creaba comunidad, esto es, proporcionaba el acceso a la unidad común. La comprensión entre sujetos implica más que la explicación la creación de entornos comunes experienciales.

\subsection{De la obcecación de creencias a la apertura de la comunión}

Regresando a nuestro tema, en lugar de arengar con discursos sobre la tolerancia, sería conveniente promover universos donde las experiencias opuestas puedan, primero, exponerse para, luego, aceptarse y comprenderse por todos. Se trataría de generar comunidades experienciales donde la posibilidad del atentado sea incomprensible y, por ende, impensable e impracticable. Como destaca Habermas: "El principio de tolerancia de las partes en conflicto llegan a un entendimiento mutuo mirándose a una misma altura de los ojos" (p. 271) En la comunidad, no es factible ni deseable eliminar a alguien que camina al lado y ayuda en la comprensión de una totalidad más grande que cada individualidad: su eliminación limitaría las capacidades comprensivas propias o del grupo dificultando el propio peregrinaje.

La dinámica propuesta abarca un proceso, primero, de integración (siendo conscientes de que pueden existir conflictos iniciales) y, en última instancia, de transculturalidad donde el esquema «nosotros frente a vosotros» se desarme ante la edificación de un nosotros plural sin un afuera.

Esta llamada se hace más importante en la medida en que el objeto al que estamos haciendo referencia es Dios, entidad que, como ha señalado Jean Luc Marion, es más que un ente (Marion 2010) es un "fenómeno saturado" 75 . Por tanto, no se puede ac-

75 Esto conduce a la complejidad del hecho religioso como hace ver Martín Velasco en su Fenomenología de la religión: "El término «religión» designa principalmente un hecho humano complejo y especifico: un conjunto de sistemas de creencias, de prácticas, de símbolos, de estructuras sociales a través de las cuales el hombre, en las diferentes épocas y culturas, vive su relación con un mundo específico: el mundo de lo sagrado. Este hecho se caracteriza externamente por su complejidad — en él se ponen en juego todos los niveles de la conciencia humana-" (Martín Velasco 2006, 75-76). 
ceder a él por medio de la argumentación. De acuerdo con el francés, serían necesarias la donación y el amor para comprenderlo (Marion 2005).

En suma, la compresión comunitaria experiencial implica un proceso en el que se comparte un camino común más que una lucha de perspectivas subjetivistas y clausuradas y clausurantes. Este camino genera experiencias comunes y disuelve el encono entre contenedores creenciales incompatibles. Esto se produce no por convencimiento argumental sino la progresiva proximidad de dos o más atraídos por un foco común más grande que cualquiera de las individualidades.

\section{Bibliografía}

Antón, J.A., El ser y los símbolos, Madrid, 2010.

Armstrong, K., Los orígenes del fundamentalismo (en el judaísmo, el cristianismo y el Islam), Barcelona 2009,

Avilés, J., "De los atentados de Madrid a los de París. La Unión Europea ante la amenaza yihadista, 2014-2015", Historia del presente, $\mathrm{n}^{\circ}$ 25, 2015, pp. 105-114.

Balthes, P., Wisdom as Orchestration of Mind and Virtue, Berlin, inédito.

Barrientos Rastrojo, J., "La fisiología del saber de la experiencia y los frutos de su posesión”, Themata, $\mathrm{n}^{\circ}$ 44, 2011, pp. 79-96.

- "La viabilidad de los conceptos de creencia y experiencial en Internet", Utopía y praxis latinoamericana, $\mathrm{n}^{\mathrm{o}}$ 69, 2015, pp. 53-66.

Benjamin, W., Experiencia y pobreza en Discursos interrumpidos I, Madrid, 1973.

Beuchot, M., Tratado de hermenéutica analógica, México DF, 1999.

Bolado, G., "Génesis y sentido de la creencia en Ortega y Gasset" en H. Arévalo- G. Bolado - F. La Rubia, L. (coords.), Entre Europa y América: estudios de Filosofía, Loja, 2014, pp. 87-135

Bustamante, J., "Hermenéutica experiencial en el Zhuangzi: La infinita proximidad de lo real en el taoísmo filosófico", Utopía y praxis latinoamericana, $\mathrm{n}^{\circ} 72,2016$, pp. 53-68.

Castro, J.M., Caminar con y hacia Sócrates: un itinerario entre Bernard Lonergan y Kitarô Nishida, Comillas, 2015.

Comte-Sponville, A., El amor. La soledad, Barcelona, 2000.

Curnow, T., "Metamorphosis", Utopía y praxis latinoamericana, n 72, 2016, pp. 41-51.

- Wisdom in the ancient world, Londres, 2010.

Durand, G., La imaginación simbólica, Buenos Aires, 1968.

Esquirol, J.M., El respeto o la mirada atenta, Barcelona, 2006.

- La resistencia intima, Barcelona, 2015.

Ferraris, M., Historia de la hermenéutica, Madrid, 2000.

Gadamer, H.G., Verdad y método, Salamanca, 1977.

Grondin, J., Introducción a la hermenéutica filosófica, Barcelona, 1999.

Habermas, J., Mundo de la vida, politica y religión, Madrid 2015.

Heredia, A., "La sutileza en la construcción de la imagen del mundo", Paradigma, n 16 , 2014, pp. 22-24.

Heidegger, M., Caminos del bosque, Madrid, 2010.

Israel, E. - Pomares, R.E., "Indicadores de calidad en el tratamiento del atentado del maratón de Boston en el periodismo televisivo español", Estudios sobre el Mensaje Periodístico , vol. 21, 2015, pp. 231-247.

Julien, F., Un sabio no tiene ideas o el otro de la filosofía, Madrid, 2001. 
Krause, N., "Assessing the relationships among wisdom, humility, and life satisfaction", Journal of Adult Development, vol. 23, 2016, pp. 1-10.

Korstanje, M.E., "Preemption and Terrorism. When the Future Governs", Cultura, no 10(1), 2013, pp. 167-184.

- "Seguridad y terrorismo en un mundo global: discutiendo la perspectiva según Sevil Somnez, Abraham (Abe) Pizam y Peter Tarlow", Études caribéennes, no 31-32, 2015, disponible online en http://etudescaribeennes.revues.org/7530, último acceso 17 de junio de 2016.

Lacoste, J.Y., Experiencia y absoluto, Salamanca, 2012.

Ladrière, J. La articulación del sentido, Salamanca 2001.

Llopis, B. et al. (eds.), Identidades cuestionadas: coexistencias y conflictos religiosos en el mediterráneo, Valencia, 2016.

Marion, J.L., Acerca de la donación. Una perspectiva fenomenológica, Buenos Aires, 2005.

- Dios sin el ser, Pontevedra, 2010.

Martín Velasco, J. Introducción a la fenomenología de la religión, Madrid, 2006.

Navarro, A. "A diez años del horror. Una década de los trágicos atentados contra los trenes de Cercanías en Madrid", El siglo de Europa, n 1054, 2014, pp. 32-38.

Nishida, K., Indagación del bien, Barcelona, 1995.

Ortega y Gasset, J., La idea de principio en Leibniz y la evolución de la teoría deductiva en Obras completas 8 Madrid, 1994, pp. 59-353

Palmer, R., ¿Qué es la hermenéutica? Teoría de la interpretación en Schleiermacher, Dilthey, Heidegger y Gadamer, Madrid, 2002.

Panikkar, R., Iconos del misterio, Barcelona, 2001.

Ricoeur, P., El conflicto de las interpretaciones: ensayos hermenéutica, Buenos Aires 2003.

Romano, C., El acontecimiento y el mundo, Salamanca 2012.

- Lo posible y el acontecimiento, Santiago de Chile 2008.

Schleiermacher, F.D.E., Discursos de hermenéutica, Pamplona, 1999.

Spiegel, J.S., "Open-mindedness and intellectual humility", Theory and Research in Education, 2012, vol. 10, pp. 27-38.

Zambrano, M. Delirio y destino, Madrid, 1989.

- Hacia un saber sobre el alma, Madrid, 2004.

- Horizontes del liberalismo, Madrid, 1996a.

- La agonía de Europa, Madrid, 2000.

- La confesión: género literario, Madrid, 1995.

- Pensamiento y poesía en la vida española, Madrid, 1996b.

Zubiri, X., El hombre y dios, Madrid, 1984. 